\title{
Arctic Sea Surface Salinity Retrieval from SMOS measures
}

J. Martínez, C. Gabarró, E. Olmedo, V. González-Gambau, C. González-Haro, A. Turiel, J. Ballabrera-Poy, L. Bertino, R.P. Raj, J. Xie, R. Catany, M. Arias, R. Sabia, W. Tang, S. Yueh

\section{Arctict}

Salinity

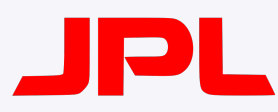

Jet Propulsion Laboratory California Institute of Technology
PIf $B E C$

ARGANS

Barcelona Expert Center

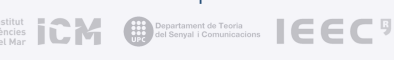




\section{Arctic+ project: goals}

The ESA Arctic+ Salinity project will contribute to reduce the knowledge gap in the characterization of the freshwater flux changes in the Arctic region

The objectives of the project are the following:

- Improve algorithm to produce the best quality SSS product of the Arctic region of well-characterized accuracy.

- Combine SMOS and SMAP data to improve the radiometric accuracy and the characterization of the product biases and stability.

- Distribute a long term salinity dataset (starting at 2011)

- Assess the relation between the dynamics of SMOS salinity with land and ocean freshwater fluxes (Greenland and glacier flows \& rivers and EP). Quantify the freshwater fluxes with SSS products.

- Assess the impact of the new data in a data assimilation system (the TOPAZ4 system, both in forecast and reanalysis mode) with the idea that if an improvement is demonstrated the assimilation of SMOS \& SMAP products on TOPAZ will become the new Arctic reanalysis and forecast products on the CMEMS portal.
Dec. 2018 - Jun. 2020

Arctic+

Salinity

ARGANS

Argans Ltd

CSIC

ICMM

Barcelona Expert Center Institute of Marine Sciences

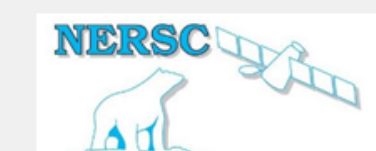

Nansen Environmental and Remote Sensing Center

http://arcticsalinity.argans.co.uk 


\section{Arctic+ project: current status}

Current version of BEC Arctic product corresponds to 2.0. Although the major features of the inter-annual SSS variations observed by the thermosalinographs are also captured by this version of the Arctic SMOS SSS maps, salinity gradients are only partially resolved.

Now we are generating v3.0 pre-release. This is a version intended for internal tests.

Gradients and rivers mouth have been highly improved as compared with previous product

\section{Work in progress.}

New version of the Arctic SSS product (v3.0) will be available before the end of 2019 at BEC ftp server

http://bec.icm.csic.es/bec-ftp-service/
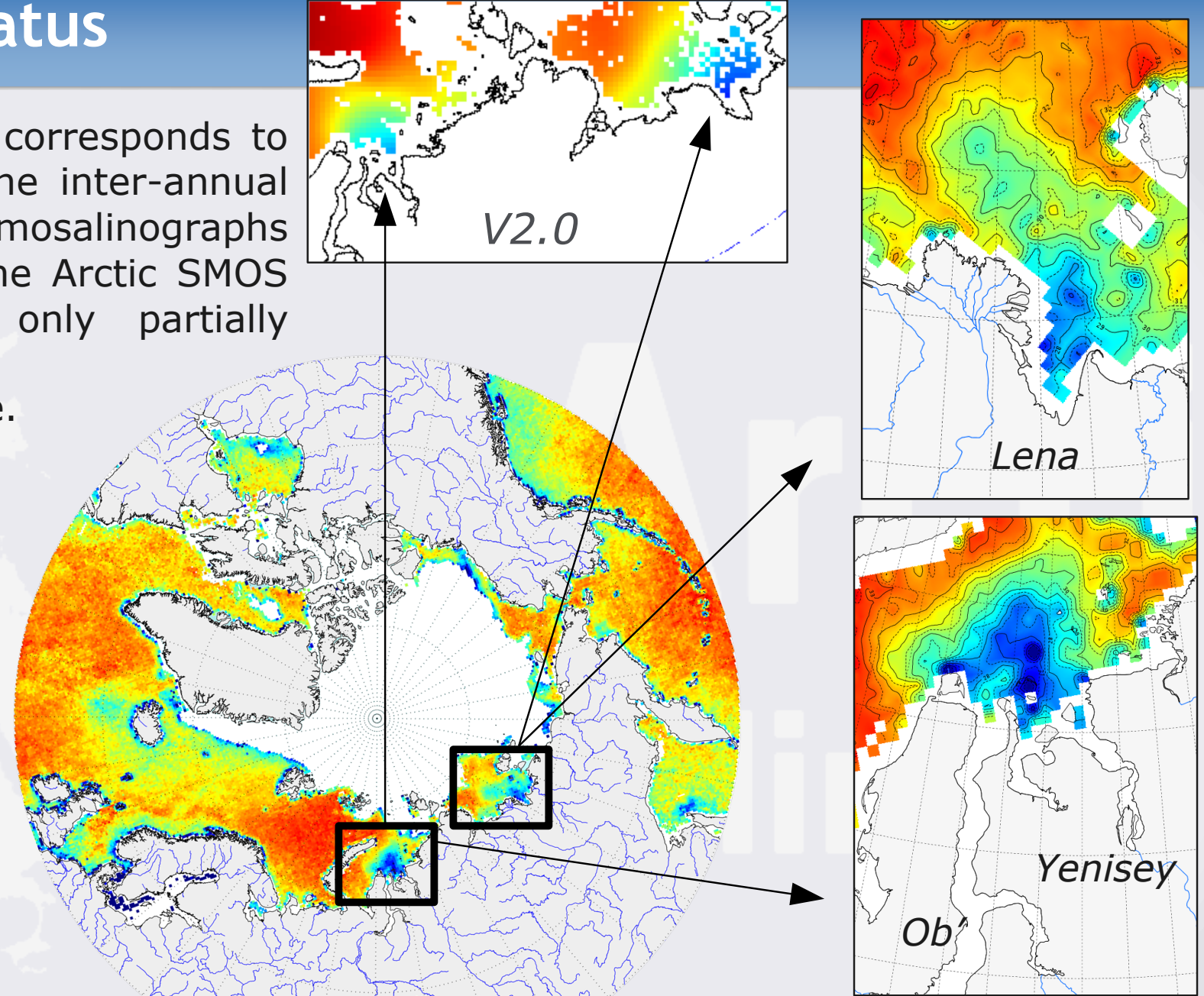

pre-releaseV 3.0 


\section{Arctic+ project: assimilation}

Assimilation. Feasibility study with previous BEC product

In the Beaufort Sea, the summer SSS from the BEC product has the smallest - saline - bias ( $\sim 0.6 \mathrm{psu})$ with the smallest root mean squared difference (RSMD) of $2.6 \mathrm{psu}$. This suggests a potential value of assimilating this product into the forthcoming Arctic reanalyses.

Evaluation of Arctic Ocean surface salinities from SMOS and two CMEMS reanalyses against in-situ data sets, Ocean Sci. Discuss., Xie, J., Raj, R. P., Bertino, L., Samuelsen, A., and Wakamatsu, T. https://doi.org/10.5194/os-2018-163, in review, 2019.

Monthly average

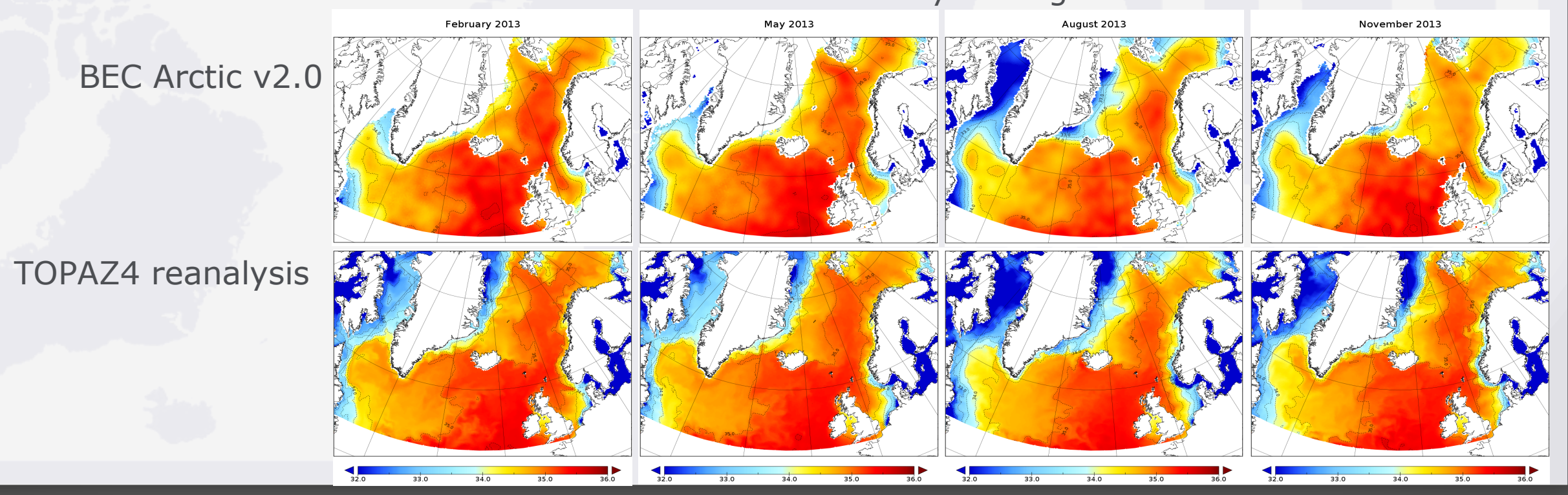

